\title{
Comparison of indirect markers of insulin resistance in adult patients with Double Diabetes
}

\author{
Aldo Ferreira-Hermosillo ${ }^{* *}$ (D), Raúl Ibarra-Salce ${ }^{2}$, Joshua Rodríguez-Malacara ${ }^{1}$ and Mario Antonio Molina-Ayala ${ }^{2}$
}

\begin{abstract}
Background: The presence of insulin resistance (IR) and metabolic syndrome (MS) in patients with type 1 diabetes (T1D) has been called "double diabetes". This entity increases the risk for development of micro and macrovascular complications and cardiovascular mortality. The gold standard for IR quantification is the hyperinsulinemic euglycemic clamp (HEC) but it is invasive, time-consuming and not available in the majority of the clinical settings. Because of this, some formulas for IR quantification have been proposed. We aimed to compare the utility of those methods for MS detection in patients with T1D.

Methods: We conducted a cross-sectional study in 112 patients with T1D and determined the presence of MS using the Joint Statement Criteria. We calculated the estimated glucose disposal rate (eGDR), estimated insulin sensitivity index (elS), natural logarithm of glucose disposal rate (InGDR), triglyceride/high-density lipoprotein cholesterol ratio (TG/HDL-c), visceral adipose index (VAl) and waist-to-height ratio (WHtR), and compared among patients with and without MS using Student t-test or Mann-Whitney U test. Receiver Operating Characteristics curves for the different indexes were used to identify the best cut-off points for MS detection.
\end{abstract}

Results: Thirty three percent of the patients were considered to have MS. The patients with MS had lower eGDR (5.49 [4.37-6.80] vs. 8.93 [8.03-9.94] mg/kg/min), elS (2.89 [1.54-3.54] vs. 3.51 [2.68-4.68]) and InGDR (1.69 0.27 vs. $1.95 \pm 0.21 \mathrm{mg} / \mathrm{kg} / \mathrm{min})$, and higher WHtR (0.55 \pm 0.05 vs. $0.50 \pm 0.05)$, VAl (3.4 [1.92-5.70] vs. 1.39 [0.97-1.92]) and TG/HDL-c (3.78 [2.63-5.73] vs. 1.77 [1.18-2.75]) in comparison with patients without MS. The cut-off points of TG$\mathrm{HDL}-\mathrm{c}>2.0, \mathrm{eGDR}<7.32 \mathrm{mg} / \mathrm{kg} / \mathrm{min}, \mathrm{InGDR}<1.8 \mathrm{mg} / \mathrm{kg} / \mathrm{min}, \mathrm{VAl}>1.84, \mathrm{WHtR}>0.52$ and $\mathrm{elS}<2.92 \mathrm{had}$ a sensitivity of $86,85,82,77$ and $70 \%$ respectively, for MS detection. The TG/HDL-c, InGDR and elS sensitivity changed depending on sex meanwhile eGDR, WHtR and VAI did not need adjust by sex.

Conclusion: Our data show that an eGDR $<7.32 \mathrm{mg} / \mathrm{kg} / \mathrm{min}$ have the highest sensitivity and specificity to detect the presence of MS in patients with T1D.

Keywords: Diabetes mellitus, type 1, Metabolic syndrome, Insulin resistance

\footnotetext{
* Correspondence: aldo.nagisa@gmail.com

'Unidad de Investigación Médica en Enfermedades Endocrinas, Hospital de Especialidades Centro Médico Nacional Siglo XXI, Instituto Mexicano del Seguro Social (IMSS), Cuauhtémoc No. 330, Colonia Doctores, Mexico City, Mexico

Full list of author information is available at the end of the article
}

(c) The Author(s). 2020 Open Access This article is licensed under a Creative Commons Attribution 4.0 International License, which permits use, sharing, adaptation, distribution and reproduction in any medium or format, as long as you give appropriate credit to the original author(s) and the source, provide a link to the Creative Commons licence, and indicate if changes were made. The images or other third party material in this article are included in the article's Creative Commons licence, unless indicated otherwise in a credit line to the material. If material is not included in the article's Creative Commons licence and your intended use is not permitted by statutory regulation or exceeds the permitted use, you will need to obtain permission directly from the copyright holder. To view a copy of this licence, visit http://creativecommons.org/licenses/by/4.0/ The Creative Commons Public Domain Dedication waiver (http://creativecommons.org/publicdomain/zero/1.0/) applies to the data made available in this article, unless otherwise stated in a credit line to the data. 


\section{Background}

Type 1 diabetes (T1D) is an autoimmune disease characterized by pancreatic $\beta$-cell destruction, resulting in absolute insulin deficiency. On the other hand, type 2 diabetes (T2D) is associated with varying degrees of insulin resistance (IR) and relative insulin deficiency [1]. Recently, some studies have reported patients with T1D that develop clinical features of T2D as obesity, hypertension, dyslipidemia, or metabolic syndrome (MS) [2]. This phenomena is called "double diabetes" and has been associated with an increased rate of chronic complications and cardiovascular diseases in patients with T1D [3, 4].

The gold standard to measure insulin resistance is the glucose disposal rate (GDR) derived from the hyperinsulinemic euglycemic clamp (HEC) $[5,6]$. However, clamps are invasive and time-consuming procedures, which are mainly performed for research purposes. In patients with T2D, indirect methods as the homeostasis model assessment of insulin resistance (HOMA-IR) and the Matsuda index have demonstrated to be useful for the assessment of IR [7], but their usage is limited in patients with T1D because both require a preserved $\beta$-cell function. Other formulas have been proposed for the assessment of IR in patients with T1D.

The first validated and most used method is the estimated glucose disposal rate (eGDR) [8], in which lower rates correlate with greater IR [9]. Furthermore, in patients with T1D it predicts the development of chronic complications as nephropathy, peripheral vascular disease and coronary artery disease [10]. In the Mexican population, our group found that an eGDR below 7.32 $\mathrm{mg} / \mathrm{kg} / \mathrm{min}$ had a $80 \%$ sensitivity for MS diagnosis [11]. We also demonstrated that the waist-to-height ratio (WHtR, with a cut-off point of $>0.52$ ) is helpful to predict the presence of MS [12]. Other available methods are the insulin sensitivity prediction equation (eIS) [13]; the natural logarithm of the GDR [14]; the triglycerides/ high density lipoprotein cholesterol (TG/HDL-c) ratio and the visceral adiposity index (VAI) [15]. All of these indexes are simple to calculate, they are based on widely available clinical parameters, and they have been validated in different populations, showing adequate sensitivities and specificities when compared to the HEC. Nevertheless, no studies have compared their utility for the detection of MS. The purpose of this study was to evaluate and compare the utility of those indexes for the detection of MS in patients with T1D and to propose specific cut-off values for this population.

\section{Methods}

We performed a cross-sectional evaluation in all the patients of the Type 1 Diabetes Clinic from January 2018 to January 2019 (Hospital de Especialidades Centro
Médico Nacional Siglo XXI, a tertiary care referral center). We included patients that were 18 years of age or older at the time of the study, with at least 3 visits per year to the clinic and no change in insulin dose during the same time. Patients with incomplete records or follow-up, poor treatment adherence and primary dyslipidemias were excluded. We also excluded patients in treatment with metformin, thiazolidinediones or SGLT2 (sodium glucose co-transporter type 2) inhibitors. Data such as age at diagnosis, family history, tobacco or alcohol use, quantity of consumed kilocalories, minutes of exercise performed, and type and doses of insulin where directly interrogated to each participant. The presence of microvascular complications (nephropathy, neuropathy and retinopathy), and gout was obtained from their clinical records. The study completed all the requirements by the local ethics committee and was conducted in accordance with the Declaration of Helsinki regarding Ethical Principles for Medical Research Involving Humans. All the patients gave their written consent.

\section{Diagnostic criteria for MS}

Patients were considered to have MS when they presented 3 or more of the Joint Statement Criteria [16]: hypertriglyceridemia (triglycerides [TG] > $150 \mathrm{mg} / \mathrm{dl}$ [1.7 $\mathrm{mmol} / \mathrm{l}]$ or in treatment for this condition); low serum high-density lipoprotein cholesterol (HDL-c $<40 \mathrm{mg} / \mathrm{dl}$ [1.03 mmol/l] in men or $<50 \mathrm{mg} / \mathrm{dl}[1.29 \mathrm{mmol} / \mathrm{l}]$ in women]; hypertension (blood pressure higher than 130/ $85 \mathrm{mmHg}$ or in treatment for this condition); and central obesity (defined using WC), as previously described [11]. All the patients met the criteria of high fasting glucose since they had T1D.

\section{Anthropometric measurements}

A single investigator registered the weight $(\mathrm{kg})$, height (meters), and WC (cm) and calculated the WHtR, waistto-hip ratio (WHR) and body mass index (BMI). BMI was used to classify weight groups, according to the World Health Organization (WHO) criteria [17]. Blood pressure was determined as the average value after two measurements with a 5-min difference between them.

\section{Biochemical determinations}

We analyzed glucose, total cholesterol (TC), HDL-c and TG with a commercially available kit using photocolorimetry. Glycated hemoglobin (HbA1c) was evaluated by turbidimetric immunoanalysis [11]. Low-density lipoprotein cholesterol (LDL-c) was calculated with Friedewald formula: LDL-c $(\mathrm{mg} / \mathrm{dl})=\mathrm{TC} \mathrm{mg} / \mathrm{dl}-(\mathrm{HDL}-\mathrm{c} \mathrm{mg} / \mathrm{dl}+$ $\mathrm{TG} \mathrm{mg} / \mathrm{dl} / 5$ ) if TG were $<400 \mathrm{mg} / \mathrm{dl}$ [18]. Serum creatinine was evaluated with a commercial kit and glomerular filtration rate (GFR) was estimated using CKD-EPI equation [19]. 


\section{Insulin resistance quantification methods}

Insulin resistance was calculated using the following methods:

a) Estimated glucose disposal rate (eGDR): 24.31 (12.22 x waist-to-hip ratio [WHR]) - (3.29 x hypertension [defined as $0=$ no, $1=$ yes] $)-(0.57 \mathrm{x}$ HbA1c [\%]). Using this formula, a lower eGDR level indicates greater IR [9].

b) Estimated insulin sensitivity (eIS): exp. 4.1075-0.1299 (waist, $\mathrm{cm}$ ) - 1.05819 (daily insulin dose, $\mathrm{U} / \mathrm{kg}$ ) 0.00354 (TG, mg/dl) - 0.00802 (DBP, mmHg). Lower values indicate decreased insulin sensitivity [13].

c) Natural logarithm of glucose disposal rate $(\operatorname{lnGDR})=4.964-0.121 \times \mathrm{HbA} 1 \mathrm{c}(\%)-0.012 \times$ diastolic blood pressure, DBP (mmHg) - $1.409 \mathrm{x}$ WHR. A low lnGDR indicates greater IR [14].

d) TG/HDL-c ratio was calculated from the lipid profile by dividing TG by HDL-c using values in units of $\mathrm{mg} / \mathrm{dl}$. Higher ratios suggest IR [15].

e) Visceral adiposity index (VAI) was calculated for women $=[\mathrm{WC} / 36.58+(1.89 * \mathrm{BMI})] *(\mathrm{TG}$ in $\mathrm{mg} /$ $\mathrm{dl} / 0.81) *(1.52 / \mathrm{HDL}-\mathrm{c}$ in $\mathrm{mg} / \mathrm{dl})$ and for men $=[\mathrm{WC} / 39.68+(1.88 * \mathrm{BMI})] *(\mathrm{TG}$ in $\mathrm{mg} / \mathrm{dl} /$ $1.03) *(1.31 / \mathrm{HDL}-\mathrm{c}$ in $\mathrm{mg} / \mathrm{dl})$. Higher VAI values indicate IR [15].

\section{Sample size calculation}

We calculated the sample size using the comparison of proportions formula, considering that $37 \%$ of our patients with T1D had metabolic syndrome as previously reported [12]. For this purpose, we considered a confidence level of $95 \%$, margin of error of $5 \%$ and a limited population size of 150 patients (representing all the patients of our Clinic). The sample size required was 106 patients.

\section{Statistical analysis}

Data were analyzed using SPSS v. 23. We evaluated normality using a Kolmogorov-Smirnov test. Results are expressed as mean \pm standard deviation (SD) or medians (interquartile ranges). Associations between quantitative variables were assessed with Student t test or MannWhitney U test. Qualitative variables (as the frequency of hypertension, hypertriglyceridemia, low HDL-c levels, obesity, gout, hypercholesterolemia, microvascular diseases, and KDIGO [Kidney Disease: Improving Global Outcomes] stages in patients with or without MS) were associated with chi-squared or Fisher's test. Receiver Operating Characteristic (ROC) curves were used to identify the best cutoff point of each IR index using Youden formula (sensitivity + specificity -1 ) [20]. We also evaluated the area under the ROC curve (AUC, with
95\% confidence intervals). A $p<0.05$ was considered to be significant.

\section{Results}

We evaluated 112 patients during the study period. The median age of our population was 35 years (26-43 years), $66 \%$ were females and the median time since diagnosis was 22 years (15-29 years). Regarding their family history, $75 \%$ had first-degree relatives with T2D, 64\% with hypertension and $10 \%$ with dyslipidemia. Twenty two percent of the patients smoke more than one cigarette per day and $27 \%$ reported regular alcohol consumption. In the whole group 33\% had hypertension, 14\% hypertriglyceridemia, 31\% had low HDL-c levels (according sex) and $21 \%$ had hypercholesterolemia (defined as TC levels higher than $200 \mathrm{mg} / \mathrm{dl}$ ). Using the WHO classification, $31 \%$ of the patients had overweight or obesity, and according to the IDF proposed cut-off points, $36 \%$ had central obesity [median WC in men of $87 \mathrm{~cm}(81-97 \mathrm{~cm})$ and in women of $81 \mathrm{~cm}(75-88 \mathrm{~cm})]$. The patients reported a previous assessment by a nutritionist with a diet adherence of $70 \%(43-80 \%)$. Only $18 \%$ practiced regular exercise (more than $150 \mathrm{~min}$ per week). All the patients were exclusively treated with insulin, with an intensive regimen: $60 \%$ used long-acting insulin analogue (glargine $100 \mathrm{U} /$ $\mathrm{ml}), 36 \%$ used neutral protamine Hagedorn insulin (NPH) and $2 \%$ were on treatment with mixed insulin. Regarding prandial insulin, $83 \%$ used lispro and $16 \%$ used regular insulin. The median dose of insulin was $43 \mathrm{U} /$ day $(32-60 \mathrm{U} /$ day) or $0.70 \mathrm{U} / \mathrm{kg} /$ day $(0.54-0.96 \mathrm{U} / \mathrm{kg} /$ day).

According the Joint Statement Criteria, 33\% of the patients $(n=37)$ were considered to have MS. Table 1 compares the baseline characteristics of the groups with and without MS. We observed that patients with MS were older, had higher weight, BMI, waist and hip circumference (with concomitant higher WHR), had higher concentrations of triglycerides and higher systolic and diastolic blood pressure in comparison with the patients without MS. We also observed that patients with MS had lower HDL-c concentration, but this difference was only significant in females. When comparing patients with and without MS, there were no significant differences in family history of T2D (74\% vs. 75\%), hypertension (71 vs. $58 \%$ ) or dyslipidemias (12 vs. $1 \%)$, prevalence of hypothyroidism (49\% vs. $36 \%$ ), and type and doses of insulin $(72 \%$ vs. $54 \%$ of patients with vs. without MS were on treatment with glargine, $64 \%$ vs. $73 \%$ were on treatment with lispro, respectively). There were no differences in glucose or HbA1c levels among groups. As expected, the prevalence of all the components of MS, including gout, were different among groups. Sixty percent of patients with MS in comparison with $32 \%$ of patients without MS had overweight or obesity. Despite there were no differences among groups in the prevalence of previous 
Table 1 Baseline characteristics of the population comparing patients with and without MS

\begin{tabular}{|c|c|c|c|c|}
\hline & Total population $(n=112)$ & Without MS $(n=75)$ & With MS $(n=37)$ & $p^{\mathrm{a}}$ \\
\hline Female sex & $66(74)$ & $64(48)$ & $70(26)$ & NS \\
\hline Age, years & $35(26-43)$ & $34(25-40)$ & $37(31-47)$ & 0.035 \\
\hline Time since diagnosis, years & $22(15-29)$ & $22(14-28)$ & $24(16-38)$ & NS \\
\hline \multicolumn{5}{|l|}{ Insulin dose: } \\
\hline U/day & $43(32-60)$ & $42(31-54)$ & $52(34-65)$ & NS \\
\hline U/kg/day & $0.70(0.54-0.96)$ & $0.69(0.53-0.96)$ & $0.72(0.53-0.93)$ & NS \\
\hline Weight, kg & $63(55-71)$ & $60(54-69)$ & $66(58-78)$ & 0.007 \\
\hline Height, m & $1.62 \pm 0.89$ & $1.62 \pm 0.92$ & $1.62 \pm 0.85$ & NS \\
\hline $\mathrm{BMI}, \mathrm{kg} / \mathrm{m}^{2}$ & $24.2 \pm 3.3$ & $23.4 \pm 2.7$ & $25.9 \pm 3.8$ & $<0.001$ \\
\hline$W C, \mathrm{~cm}$ & $84(78-91)$ & $79(74-87)$ & $88(83-97)$ & $<0.001$ \\
\hline Female & $81(75-88)$ & $78(74-85)$ & $85(81-92)$ & 0.002 \\
\hline Male & $87(81-97)$ & $83(78-87)$ & $97(90-102)$ & 0.001 \\
\hline Hip circumference, $\mathrm{cm}$ & $98(93-103)$ & $97(92-101)$ & $100(94-105)$ & 0.014 \\
\hline WHR & $0.86 \pm 0.08$ & $0.84 \pm 0.06$ & $0.89 \pm 0.07$ & $<0.001$ \\
\hline Female & $0.83 \pm 0.06$ & $0.82 \pm 0.06$ & $0.86 \pm 0.05$ & 0.028 \\
\hline Male & $0.90 \pm 0.07$ & $0.87 \pm 0.05$ & $0.96 \pm 0.06$ & $<0.001$ \\
\hline $\mathrm{SBP}, \mathrm{mmHg}$ & $106 \pm 15$ & $104 \pm 14$ & $110 \pm 17$ & 0.027 \\
\hline $\mathrm{DBP}, \mathrm{mmHg}$ & $71 \pm 9$ & $69 \pm 8$ & $74 \pm 10$ & 0.017 \\
\hline $\mathrm{FBG}, \mathrm{mg} / \mathrm{dl}$ & $133(80-222)$ & 138 (79-232) & $126(85-195)$ & NS \\
\hline $\mathrm{HbA} 1 \mathrm{c}, \%$ & $8.61 \pm 1.73$ & $8.4 \pm 1.6$ & $9.0 \pm 1.8$ & NS \\
\hline $\mathrm{TG}, \mathrm{mg} / \mathrm{dl}$ & $113(78-172)$ & $94(70-135)$ & $172(123-249)$ & $<0.001$ \\
\hline $\mathrm{TC}, \mathrm{mg} / \mathrm{dl}$ & $169(142-195)$ & $169(142-190)$ & $165(141-204)$ & NS \\
\hline $\mathrm{HDL}-\mathrm{c}, \mathrm{mg} / \mathrm{dl}$ & $51(44-63)$ & $56(48-68)$ & $45(37-49)$ & $<0.001$ \\
\hline Female & $57(45-67)$ & $61(51-72)$ & $45(38-53)$ & $<0.001$ \\
\hline Male & $49(40-54)$ & $49(40-56)$ & $47(35-49)$ & NS \\
\hline $\mathrm{LDL}-\mathrm{c}, \mathrm{mg} / \mathrm{dl}$ & $89(73-111)$ & $88(73-110)$ & $92(75-111)$ & NS \\
\hline $\mathrm{GFR}, \mathrm{ml} / \mathrm{min} / 1.73 \mathrm{~m}^{2} \mathrm{SC}$ & $74.7(43.7-106.8)$ & $77.6(57.6-116.6)$ & $52.6(28.9-91.1)$ & 0.029 \\
\hline \multicolumn{5}{|c|}{ Metabolic Syndrome and Comorbidities, \%(n) } \\
\hline Hypertension & $33(37)$ & $16(12)$ & $68(25)$ & $<0.001$ \\
\hline Hypertriglyceridemia & $14(16)$ & 0 & $43(16)$ & $<0.001$ \\
\hline Low HDL-C & $31(35)$ & $16(12)$ & $62(23)$ & $<0.001$ \\
\hline Central obesity & $36(41)$ & $23(17)$ & $65(24)$ & $<0.001$ \\
\hline Female & $26(30)$ & $17(13)$ & $46(17)$ & $<0.001$ \\
\hline Male & $10(11)$ & $5(4)$ & $19(7)$ & 0.020 \\
\hline Obesity (BMI) & & & & 0.029 \\
\hline Normal & $65(72)$ & $74(55)$ & $46(17)$ & \\
\hline Overweight & $24(27)$ & $19(14)$ & $35(13)$ & \\
\hline Class I Obesity & $7(7)$ & $4(3)$ & $14(5)$ & \\
\hline Class II Obesity & $1(1)$ & 0 & $3(1)$ & \\
\hline Hypercholesterolemia & $21(24)$ & $13(10)$ & $38(14)$ & 0.006 \\
\hline Gout & $4(5)$ & 0 & $14(5)$ & 0.003 \\
\hline \multicolumn{5}{|l|}{ Microvascular disease } \\
\hline Nephropathy & $14(16)$ & $12(9)$ & $19(7)$ & NS \\
\hline Neuropathy & $13(14)$ & $9(7)$ & $19(7)$ & NS \\
\hline
\end{tabular}


Table 1 Baseline characteristics of the population comparing patients with and without MS (Continued)

\begin{tabular}{|c|c|c|c|c|}
\hline & Total population $(n=112)$ & Without MS $(n=75)$ & With MS $(n=37)$ & $p^{a}$ \\
\hline Retinopathy & $7(8)$ & $5(4)$ & $11(4)$ & NS \\
\hline KDIGO Stages: & & & & 0.044 \\
\hline Stage 1 & $47(53)$ & $51(38)$ & $41(15)$ & \\
\hline Stage 2 & $25(28)$ & $29(22)$ & $16(6)$ & \\
\hline Stage 3 & $17(19)$ & $15(11)$ & $22(8)$ & \\
\hline Stage 4 & $6(7)$ & $4(3)$ & $11(4)$ & \\
\hline Stage 5 & $4(5)$ & $1(1)$ & $11(4)$ & \\
\hline
\end{tabular}

Data are presented as $\%(n)$, mean \pm SD or median (IQR). * Statistically different among patients with or without MS with Student $t$ test, Mann Whitney $U$, chi squared or Fisher's test, depending on their type and distribution. MS metabolic syndrome, BMI body mass index, WC waist circumference, SBP systolic blood pressure, $D B P$ diastolic blood pressure, $F B G$ fasting blood glucose, $T G$ triglycerides, $T C$ total cholesterol, $H D L-c$ high density lipoprotein cholesterol, $L D L-c$ low density lipoprotein cholesterol, GFR glomerular filtration rate, KDIGO Kidney Disease: Improving Global Outcomes, NS not significant

diagnosis of microvascular complications, the glomerular filtration rate (GFR) was lower and the KDOQI stages were worst in patients with MS.

In Table 2, we assess if indirect methods were different among patients with and without MS. The patients with MS had lower eGDR, eIS and lnGDR values, and higher WHtR, VAI and TG/HDL-c values in comparison with patients without MS. Accordingly, a higher proportion of patients with MS had an eGDR $<7.32 \mathrm{mg} / \mathrm{kg} / \mathrm{min}(60 \%$ vs. $9 \%$ in patients without MS, $p<0.001$ ) and a WHtR $>0.52$ ( $89 \%$ vs. $55 \%$ in patients without MS, $p<0.001$ ). We also observed that eGDR and lnGDR were lower and TG/ HDL-c was higher when comparing groups by sex. Despite eIS was lower in patients with MS, this result was statistically significant only in the female patients.

We performed ROC curves for eGDR, eIS, InGDR, TG/HDL-c and VAI to determine the best cut-off points to detect MS. Table 3 depicts the best cut-off values, sensitivity, specificity, likelihood ratio positive ( $\mathrm{LR}+)$ and likelihood ratio negative (LR-) values for each index. We corroborated that a cut-off point of $<7.32 \mathrm{mg} / \mathrm{kg} / \mathrm{min}$ had the best AUC for detection of MS, followed by VAI, and TG/HDL-c. The lnGDR index in male and the TG/ HDL-c index in female had the best cut-off points for MS detection.

\section{Discussion}

Using the Joint Statement criteria, 33\% of patients with T1D in our clinic have MS. This prevalence is similar to the reported in the Metascreen Study in Italy (34\%) using the AHA/NHLBI criteria [21], with the observed in a Spanish population (32\%) using the National Cholesterol Education Program: Adult Treatment Panel III (NCEP: ATPIII) criteria [9] and with the reported in an American population in the DCCT/EDIC (Diabetes Control and Complications Trial/Epidemiology of Diabetes

Table 2 Indirect markers of IR in patients with T1D with or without MS

\begin{tabular}{|c|c|c|c|c|}
\hline & Total population & Without MS $(n=75)$ & With MS $(n=37)$ & $p^{a}$ \\
\hline eGDR, mg/kg/min & $8.39(6.53-9.68)$ & $8.93(8.03-9.94)$ & $5.49(4.37-6.80)$ & $<0.001$ \\
\hline Female & $8.47(6.79-9.92)$ & $9.68(8.35-10.15)$ & $6.32(5.1-6.99)$ & $<0.001$ \\
\hline Male & $7.78(5.47-8.79)$ & $8.69(7.37-9.2)$ & $4.41(3.91-6.48)$ & $<0.001$ \\
\hline WHtR & $0.52 \pm 0.06$ & $0.50 \pm 0.05$ & $0.55 \pm 0.05$ & 0.001 \\
\hline els & $3.27(2.30-4.31)$ & $3.51(2.68-4.68)$ & $2.89(1.54-3.54)$ & 0.007 \\
\hline Female & $3.31(2.42-4.19)$ & $3.68(2.72-4.33)$ & $2.96(1.27-3.54)$ & 0.009 \\
\hline Male & $3.14(2.24-5.1)$ & $3.40(2.28-5.27)$ & $2.85(1.78-4.73)$ & NS \\
\hline InGDR, mg/kg/min & $1.86 \pm 0.27$ & $1.95 \pm 0.21$ & $1.69 \pm 0.27$ & $<0.001$ \\
\hline Female & $1.87 \pm 0.26$ & $1.96 \pm 0.22$ & $1.69 \pm 0.27$ & 0.001 \\
\hline Male & $1.83 \pm 0.27$ & $1.93 \pm 0.22$ & $1.67 \pm 0.29$ & 0.016 \\
\hline $\mathrm{TG} / \mathrm{HDL}-\mathrm{C}$ & $2.15(1.38-3.65)$ & $1.77(1.18-2.75)$ & $3.78(2.63-5.73)$ & $<0.001$ \\
\hline Female & $1.99(1.35-3.66)$ & $1.51(1.10-2.15)$ & $3.99(2.76-5.78)$ & $<0.001$ \\
\hline Male & $2.53(1.60-3.70)$ & $2.08(1.32-3.21)$ & $3.78(2.53-5.22)$ & 0.005 \\
\hline VAl & $1.76(1.13-2.99)$ & $1.39(0.97-1.92)$ & $3.4(1.92-5.70)$ & $<0.001$ \\
\hline
\end{tabular}

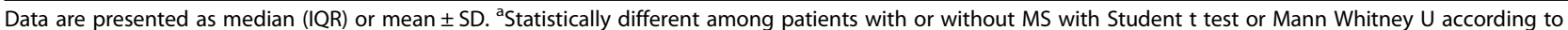
their distribution. eGDR estimated glucose disposal rate, WHtR waist-to-height ratio, elS estimated insulin sensitivity, InGDR natural logarithm of glucose disposal rate, $T G / H D L-c$ ratio triglycerides/HDL cholesterol, VAl visceral adiposity index 
Table 3 Best cut-off points for detection of MS in patients with T1D

\begin{tabular}{|c|c|c|c|c|c|c|}
\hline Index & AUC (IC95\%) & Cut-off value & Sensitivity & Specificity & LR+ & LR- \\
\hline $\mathrm{eGDR}, \mathrm{mg} / \mathrm{kg} / \mathrm{min}$ & $0.93(0.87-0.98)$ & $<7.32$ & $85 \%$ & $84 \%$ & 5.31 & 0.17 \\
\hline $\mathrm{WHtR}$ & $0.70(0.68-0.89)$ & $>0.52$ & $77 \%$ & $70 \%$ & 2.58 & 0.33 \\
\hline els & $0.68(0.56-0.81)$ & $<2.92$ & $70 \%$ & $54 \%$ & 1.52 & 0.55 \\
\hline Female & $0.72(0.57-0.86)$ & $<3.10$ & $69 \%$ & $66 \%$ & 2.02 & 0.46 \\
\hline Male & $0.63(0.40-0.87)$ & $<2.92$ & $72 \%$ & $63 \%$ & 1.94 & 0.44 \\
\hline $\operatorname{lnGDR}, \mathrm{mg} / \mathrm{kg} / \mathrm{min}$ & $0.77(0.65-0.88)$ & $<1.8$ & $82 \%$ & $73 \%$ & 3.03 & 0.24 \\
\hline Female & $0.77(0.64-0.91)$ & $<1.81$ & $80 \%$ & $69 \%$ & 2.58 & 0.28 \\
\hline Male & $0.80(0.64-0.97)$ & $<1.77$ & $88 \%$ & $80 \%$ & 4.4 & 0.15 \\
\hline TG/HDL-C & $0.83(0.76-0.91)$ & $>2.0$ & $86 \%$ & $64 \%$ & 2.39 & 0.21 \\
\hline Female & $0.86(0.77-0.95)$ & $>2.2$ & $81 \%$ & $78 \%$ & 3.68 & 0.24 \\
\hline Male & $0.78(0.63-0.93)$ & $>2.5$ & $82 \%$ & $62 \%$ & 2.15 & 0.29 \\
\hline VAl & $0.86(0.78-0.94)$ & $>1.84$ & $82 \%$ & $71 \%$ & 2.84 & 0.25 \\
\hline
\end{tabular}

eGDR estimated glucose disposal rate, WHtR waist-to-height ratio, elS estimated insulin sensitivity, InGDR natural logarithm of glucose disposal rate, TG/HDL-c ratio triglycerides/HDL cholesterol, VAl visceral adiposity index

Interventions and Complications) study (36\%) using IDF criteria [22]. We found that the most prevalent comorbidity in the patients with "double diabetes" was hypertension, even though it is a young population (mean age 35 years). The second most common comorbidity was central obesity, followed by low HDL-c levels, both of which are highly prevalent in the general Mexican population [23]. As expected, those patients also have a lower eGDR, eIS and lnGDR; and higher TG/HDL-c and VAI levels, suggesting higher IR. Among these methods, we observed that the most sensitive to detect MS in patients with T1D independently of gender, is eGDR. Additionally, in the female population the TG/HDL-c and in male population the $\ln G D R$ are also useful for this purpose.

The eGDR has been extensively validated in diverse populations [24] including in the DCCT/EDIC [22] and the EURODIAB cohorts [25]. Chillaron et al. reported that the number of MS traits inversely correlated with eGDR levels, with a Pearson correlation coefficient of $0.793(p<0.001)$ [9]. In that study, a lower eGDR was associated with coronary artery disease and retinopathy in patients with T1D [9]. In this study, we corroborated that an eGDR level below $7.32 \mathrm{mg} / \mathrm{kg} / \mathrm{min}$ had the highest sensitivity (85\%) and specificity (84\%) for MS detection, with the highest AUC in the ROC curve (AUROC 93\%). In a Spanish cohort [9], an eGDR below $8.77 \mathrm{mg} /$ $\mathrm{kg} / \mathrm{min}$ had a similar specificity as our results (85\%), but higher sensitivity (100\%). Meanwhile, Tam et al. in an American cohort found that a cut-off point of $5.6 \mathrm{mg} /$ $\mathrm{kg} / \mathrm{min}$ had a lower sensitivity (75\%) and specificity (71\%) with an AUROC of $80 \%$ for defining IR [26]. As observed, the specific cut-off point of eGDR for IR detection and its utility vary depending the ethnicity and the statistical method used for its quantification, and is usually reported among 5 to $9 \mathrm{mg} / \mathrm{kg} / \mathrm{min}$ [27].
In our study, the second most sensitive and specific method for detecting IR in total population was the lnGDR. This method was recently proposed by Zheng et al. and was calculated through a stepwise linear regression analysis using demographic and metabolic parameters. Its final formula incorporates $\mathrm{HbA1c}$, DBP and WHR, who explain over $60 \%$ of the variance of GDR (adjusted $\mathrm{R}^{2}$ of $0.61, p<0.01$ ) [14]. For this index, we observed that a cut-off point of $<1.8 \mathrm{mg} / \mathrm{kg} / \mathrm{min}$ had a high AUROC for MS detection (77\%), especially in the male population in whom a cut-off point $<1.77 \mathrm{mg} / \mathrm{kg} /$ min had an AUROC of $80 \%$. To our knowledge, this is the first study that evaluates this model in population other than Chinese. More studies are required to verify if this cut-off point has variations depending on ethnicity and its association with micro and macrovascular complications in patients with T1D.

We also assessed the TG/HDL-c and VAI indexes, whose main component are the lipids parameters [15]. Their utility in the detection of macrovascular complications has been studied in subjects with and without obesity $[28,29]$. We found that a TG/HDL-c $>2.2$ had the best sensitivity for MS in female population meanwhile a cut-off point of $>2.0$ was also sensitive but with lower specificity for total population. As VAI formula has been adjusted for gender, we did not divide it in groups. We observed that a VAI $>1.84$ had the same sensitivity as the lnGDR, but with lower specificity. In Poland, Uruska et al. studied 88 patients with T1D, with a mean age of 34 years and a median duration disease of 8 years (7-13 years). Using the HEC, IR was defined as GDR $<4 \mathrm{mg} / \mathrm{kg} / \mathrm{min}$ and it was observed in $37.5 \%$ of the patients. Patients with IR had a higher TG/HDL-c [1.6 (1.0-1.3) vs. $1.05(0.62-1.53), p=0.001]$ and VAI [2.61 (1.31-4.25) vs $1.56(0.96-2.25), p=0.002]$, in comparison 
with patients without IR [15]. In that study the sensitivity and specificity for IR or MS detection was not provided, and it is the only one conducted in adult patients with T1D.

Regarding WHtR, in this study we corroborated that a cut-off point of 0.52 had a good sensitivity and specificity. This was previously demonstrated in our population [12], where it proved to have a better diagnostic utility in comparison with the waist circumference. This method could be particularly useful in populations were the average height varies by region.

Finally, we evaluated the utility of the eIS equation. This index was developed using clinical data from 36 adults with T1D recruited from the Coronary Artery Calcification in Type 1 Diabetes (CACTI) study, with a mean age of $45 \pm 8$ years and a mean duration of diabetes of $22.6 \pm 7.8$ years [30]. The original formula included WC, daily insulin dose (U/kg/day), adiponectin, TG and DBP. However, considering that patients are not always able to fast for their clinical visits a non-fasting model was created (eIS-nf) that include WC and daily insulin dose. Furthermore, an additional model was developed excluding adiponectin (eIS-eXA), because in some clinical scenarios (as in ours) it is not routinely measured. Once developed and validated, the eIS and its variants were tested in independent adult and adolescent populations and significatively correlated with clampmeasured insulin sensitivity, even with better correlation when compared to eGDR [13]. Bjornstad et al. further observed that greater eIS at baseline predicted lower odds of developing albuminuria, diabetic retinopathy proliferative diabetic retinopathy and progression of coronary artery calcium score [31]. A specific cut-off point for detecting IR in those studies has not been provided, but in our study the cut-off points proposed for total population or divided by gender had the lower sensitivity and specificity when compared with the other methods. Nevertheless, for this study we selected eIS-eXA. Assessing cut-off point for eIS and eIS-nf is pending.

The mechanisms involved in the development of IR in patients with T1D remain unknown [32]. Some studies have proposed that obesity due non-healthy lifestyle and over-insulinization in addition to the genetic background are its main cause [32]. Meanwhile others have reported that IR is present in patients with T1D even in the absence of obesity [6]. Indeed, it seems that patients with T1D have a decreased insulin sensitivity in liver tissue (defined in the HEC as a decreased insulin-stimulated suppression of endogenous glucose production), and an increased IR in muscle (observed in the HEC as a lower whole-body glucose disposal even in the presence of lower intrahepatic fat content) and in adipose tissue (observed due impaired insulin-mediated suppression of lipolysis with subsequent increase of free fatty acids and glycerol levels) [6, 32], in comparison with healthy controls. On the other hand, it has been proposed that IR is related with glucometabolic control, diabetes duration (more than 10 years) and ethnicity [33, 34]. However, those variables were not different among patients with T1D and "double diabetes" in our study.

The limitations of some of the reported methods should be taken into account. As analyzed by Gingras et al. [4], eGDR formula incorporates hypertension, whose presence could be overestimated due some patients use antihypertensive medications for cardiac or renal prevention. Furthermore, it also incorporates the waist-to-hip ratio, a measurement that varies depending of ethnicity. Regarding limitations of $\ln G D R$ and TG/ HDL-c, the first also incorporates WHR; meanwhile a possible limitation for the second is that TG levels could widely vary depending on glycemic control. We overcome those biases, assessing that the treatment with antihypertensives was solely prescribed due to hypertension. Additionally, we believe hyperglycemia did not affect our results because there were no differences in fasting glucose or HbA1c levels among patients with or without MS.

Finally, the main limitation of our study is the lack of comparison with the HEC. Nevertheless, all the selected methods have been previously compared and validated with the gold standard. Moreover, our purpose was to identify the most accurate non-invasive and easy-toperform method that could be useful for detect patients with double diabetes in a clinical setting. Our results support the use of eGDR in Mexican patients with T1D. However, more studies with larger cohorts and different ethnic groups are required to assess the utility of the others indirect markers, especially of those recently described as the $\ln$ GDR and eIS.

\section{Conclusion}

In this Mexican cohort of adult patients with T1D an eGDR below $7.32 \mathrm{mg} / \mathrm{kg} / \mathrm{min}$ showed the highest sensitivity and specificity for detection of MS (double diabetes). In female patients the TG/HDL-c $>2.2$ and in male patients the $\ln G D R<1.77 \mathrm{mg} / \mathrm{kg} / \mathrm{min}$ are also useful for this purpose.

\footnotetext{
Abbreviations

T1D: Type 1 diabetes; T2D: Type 2 diabetes; IR: Insulin resistance; MS: Metabolic syndrome; GDR: Glucose disposal rate; HEC: Hyperinsulinemic euglycemic clamp; HOMA: Homeostatic model of assessment; eGDR: estimated glucose disposal rate; WHtR: Waist-to-height ratio; elS: estimated insulin sensitivity index; TG/HDL-c: Triglycerides/high-density lipoprotein cholesterol ratio; VAl: Visceral adiposity index; SGLT-2: Sodium glucose co-transporter type 2; AHA/NHLBI: American Heart Association/ National Heart Lung and Blood Institute; IDF: International Diabetes Federation; WC: Waist circumference; WHR: Waist-to-hip ratio; BMI: Body mass index; WHO: World Health Organization; TC: Total cholesterol; HbA1c: Glycated hemoglobin; LDL-c: Low-density lipoprotein cholesterol; InGDR: Natural logarithm of glucose disposal rate; DBP: Diastolic blood pressure; SD: Standard deviation; KDIGO: Kidney Disease: Improving Global Outcomes; ROC: Receiver Operating Characteristic; AUC: Area under curve;
} 
NPH: Neutral protamine Hagedorn insulin; GFR: Glomerular filtration rate; LR+: Likelihood positive ratio; LR-: Likelihood negative ratio; NCEP: ATPIII: National Cholesterol Education Program: Adult Treatment Panel III; DCCT/EDIC: Diabetes Control and Complications Trial/Epidemiology of Diabetes Interventions and Complications; CACTI: Coronary Artery Calcification in Type 1 Diabetes study; elS-nf: estimated insulin sensitivity non-fasting model; elS-exA: estimated insulin sensitivity without adiponectin model

\section{Acknowledgements}

Not applicable.

\section{Authors' contributions}

AHF participated in the collection and analysis of data and helped to draft the manuscript, RIS, JRM and MAMA participated in the collection of data and helped to draft the manuscript. All the authors read and approved the final manuscript.

\section{Funding}

Not applicable.

\section{Availability of data and materials}

The data analyzed in the study are available from the corresponding author on reasonable request.

\section{Ethics approval and consent to participate}

The study was approved by the Local Research and Ethics Committee (Comité Local de Investigación y Ética en Investigación en Salud) of the Instituto Mexicano del Seguro Social (IMSS Registry number R-2019-3601-11). The procedures are in compliance with local ethical regulations, the Mexican Law of General Health regarding Health Research, the institutional regulations, and the Declaration of Helsinki of 1975 and its amendments. It is also in compliance with the currently approved international codes and norms regarding Good Clinical Practice in Clinical Investigation. The protocol and the aim of the study were fully explained to the subjects, who gave their written consent.

\section{Consent for publication}

Not applicable.

\section{Competing interests}

AFH is an Associate Editor of this journal, and he had no role in the handling of the manuscript through publication. The other authors declare that they have no competing interests.

\section{Author details \\ ${ }^{1}$ Unidad de Investigación Médica en Enfermedades Endocrinas, Hospital de Especialidades Centro Médico Nacional Siglo XXI, Instituto Mexicano del Seguro Social (IMSS), Cuauhtémoc No. 330, Colonia Doctores, Mexico City, Mexico. ${ }^{2}$ Servicio de Endocrinología, Hospital de Especialidades Centro Médico Nacional Siglo XXI, Instituto Mexicano del Seguro Social (IMSS), Cuauhtémoc No. 330, Colonia Doctores, Mexico City, Mexico.}

\section{Received: 4 October 2019 Accepted: 9 June 2020}

Published online: 15 June 2020

\section{References}

1. Priya G, Kalra S. A review of insulin resistance in type 1 diabetes: is there a place for adjunctive metformin? Diabetes Ther. 2018;9(1):349-61.

2. Cleland SJ. Cardiovascular risk in double diabetes mellitus--when two worlds collide. Nat Rev Endocrinol. 2012;8(8):476-85.

3. Chillaron JJ, Flores Le-Roux JA, Benaiges D, et al. Type 1 diabetes, metabolic syndrome and cardiovascular risk. Metabolism. 2014;63(2):181-7.

4. Gingras V, Leroux C, Fortin A, et al. Predictors of cardiovascular risk among patients with type 1 diabetes: a critical analysis of the metabolic syndrome and its components. Diabetes Metab. 2017;43(3):217-22.

5. DeFronzo RA, Tobin JD, Andres R. Glucose clamp technique: a method for quantifying insulin secretion and resistance. Am J Phys. 1979;237(3):E214-23.

6. Donga $\mathrm{E}$, Dekkers $\mathrm{OM}$, Corssmit EP, et al. Insulin resistance in patients with type 1 diabetes assessed by glucose clamp studies: systematic review and meta-analysis. Eur J Endocrinol. 2015;173(1):101-9.
7. Borai A, Livingstone C, Kaddam I, et al. Selection of the appropriate method for the assessment of insulin resistance. BMC Med Res Methodol. 2011;11:158.

8. Williams KV, Erbey JR, Becker D, et al. Can clinical factors estimate insulin resistance in type 1 diabetes? Diabetes. 2000;49(4):626-32.

9. Chillaron JJ, Goday A, Flores-Le-Roux JA, et al. Estimated glucose disposal rate in assessment of the metabolic syndrome and microvascular complications in patients with type 1 diabetes. J Clin Endocrinol Metab. 2009;94(9):3530-4.

10. Nystrom T, Holzmann MJ, Eliasson B, et al. Estimated glucose disposal rate predicts mortality in adults with type 1 diabetes. Diabetes Obes Metab. 2018;20(3):556-63.

11. Ferreira-Hermosillo A, Molina-Ayala M, Ramirez-Renteria C, et al. Inflammatory cytokine profile associated with metabolic syndrome in adult patients with type 1 diabetes. J Diabetes Res. 2015;2015:972073.

12. Ferreira-Hermosillo A, Ramirez-Renteria C, Mendoza-Zubieta V, et al. Utility of the waist-to-height ratio, waist circumference and body mass index in the screening of metabolic syndrome in adult patients with type 1 diabetes mellitus. Diabetol Metab Syndr. 2014;6(1):32.

13. Duca LM, Maahs DM, Schauer IE, et al. Development and validation of a method to estimate insulin sensitivity in patients with and without type 1 diabetes. J Clin Endocrinol Metab. 2016;101(2):686-95.

14. Zheng $X$, Huang $B$, Luo $S$, et al. A new model to estimate insulin resistance via clinical parameters in adults with type 1 diabetes. Diabetes Metab Res Rev. 2017;33(4). https://doi.org/10.1002/dmrr.2880.

15. Uruska A, Zozulinska-Ziolkiewicz D, Niedzwiecki $P$, et al. TG/HDL-C ratio and visceral adiposity index may be useful in assessment of insulin resistance in adults with type 1 diabetes in clinical practice. J Clin Lipidol. 2018;12(3):734-40.

16. Alberti KG, Eckel RH, Grundy SM, et al. Harmonizing the metabolic syndrome: a joint interim statement of the international diabetes federation task force on epidemiology and prevention; National Heart, Lung, and Blood Institute; American Heart Association; world heart federation; international atherosclerosis society; and International Association for the Study of obesity. Circulation. 2009;120(16):1640-5.

17. World Health Organization. Obesity: preventing and managing the global epidemic. Report of a WHO consultation. World Health Organ Tech Rep Ser. 2000;894:i-xii 1-253.

18. Friedewald WT, Levy RI, Fredrickson DS. Estimation of the concentration of low-density lipoprotein cholesterol in plasma, without use of the preparative ultracentrifuge. Clin Chem. 1972;18(6):499-502.

19. Inker $L A$, Schmid $\mathrm{CH}$, Tighiouart $\mathrm{H}$, et al. Estimating glomerular filtration rate from serum creatinine and cystatin C. N Engl J Med. 2012;367(1):20-9.

20. Akobeng AK. Understanding diagnostic tests 3: receiver operating characteristic curves. Acta Paediatr. 2007:96(5):644-7.

21. Metascreen Writing C, Bonadonna R, Cucinotta D, et al. The metabolic syndrome is a risk indicator of microvascular and macrovascular complications in diabetes: results from Metascreen, a multicenter diabetes clinic-based survey. Diabetes Care. 2006;29(12):2701-7.

22. Kilpatrick ES, Rigby AS, Atkin SL. Insulin resistance, the metabolic syndrome, and complication risk in type 1 diabetes: "double diabetes" in the diabetes control and complications trial. Diabetes Care. 2007;30(3):707-12.

23. Rangel-Baltazar E, Cuevas-Nasu L, Shamah-Levy T, et al. Association between High Waist-to-Height Ratio and Cardiovascular Risk among Adults Sampled by the 2016 Half-way National Health and nutrition survey in Mexico (ENSANUT MC 2016). Nutrients. 2019;11(6):1402.

24. Orchard TJ, Olson JC, Erbey JR, et al. Insulin resistance-related factors, but not glycemia, predict coronary artery disease in type 1 diabetes: 10-year follow-up data from the Pittsburgh epidemiology of diabetes complications study. Diabetes Care. 2003;26(5):1374-9.

25. Chaturvedi N, Sjoelie AK, Porta M, et al. Markers of insulin resistance are strong risk factors for retinopathy incidence in type 1 diabetes. Diabetes Care. 2001;24(2):284-9.

26. Tam CS, Xie W, Johnson WD, et al. Defining insulin resistance from hyperinsulinemic-euglycemic clamps. Diabetes Care. 2012;35(7):1605-10.

27. Simoniene $D$, Platukiene $A$, Prakapiene $E$, et al. Insulin resistance in type 1 diabetes mellitus and its association with Patient's micro- and macrovascular complications, sex hormones, and other clinical data. Diabetes Ther. 2020;11(1):161-74.

28. Di Bonito P, Moio N, Scilla C, et al. Usefulness of the high triglyceride-to-HDL cholesterol ratio to identify cardiometabolic risk factors and preclinical signs of organ damage in outpatient children. Diabetes Care. 2012;35(1):158-62. 
29. Amato MC, Giordano C, Galia M, et al. Visceral adiposity index: a reliable indicator of visceral fat function associated with cardiometabolic risk. Diabetes Care. 2010;33(4):920-2.

30. Schauer IE, Snell-Bergeon JK, Bergman BC, et al. Insulin resistance, defective insulin-mediated fatty acid suppression, and coronary artery calcification in subjects with and without type 1 diabetes: the CACTI study. Diabetes. 2011; 60(1):306-14.

31. Bjornstad P, Maahs DM, Duca LM, et al. Estimated insulin sensitivity predicts incident micro- and macrovascular complications in adults with type 1 diabetes over 6 years: the coronary artery calcification in type 1 diabetes study. J Diabetes Complicat. 2016:30(4):586-90.

32. Kaul $\mathrm{K}$, Apostolopoulou M, Roden M. Insulin resistance in type 1 diabetes mellitus. Metabolism. 2015;64(12):1629-39.

33. Teixeira MM, Diniz Mde F, Reis JS, et al. Insulin resistance and associated factors in patients with type 1 diabetes. Diabetol Metab Syndr. 2014;6:131.

34. Epstein EJ, Osman JL, Cohen HW, et al. Use of the estimated glucose disposal rate as a measure of insulin resistance in an urban multiethnic population with type 1 diabetes. Diabetes Care. 2013;36(8):2280-5.

\section{Publisher's Note}

Springer Nature remains neutral with regard to jurisdictional claims in published maps and institutional affiliations.

- fast, convenient online submission

- thorough peer review by experienced researchers in your field

- rapid publication on acceptance

- support for research data, including large and complex data types

- gold Open Access which fosters wider collaboration and increased citations

- maximum visibility for your research: over $100 \mathrm{M}$ website views per year

At $\mathrm{BMC}$, research is always in progress.

Learn more biomedcentral.com/submissions 